\title{
On well-posedness of a magnetization-variables model for Navier-Stokes equations with damping
}

\author{
Abdelkerim Chaabani, ${ }^{1}$ \\ ${ }^{1}$ Universite de Tunis El Manar
}

November 18, 2020

\begin{abstract}
This paper aims to establish existence and uniqueness results of weak and strong solution to the three-dimensional periodic magnetization-variables formulation to Navier-Stokes equations with damping term. Authors in precedent works addressed the question as to whether this model and similar ones without damping term possess a weak solution. In this vein, considering a damping term in the magnetization-variable formulation turned to be consequential as it enforces existence and uniqueness results. Energy methods, compactness methods are the main tools.
\end{abstract}

\section{Hosted file}

main doc pdf.pdf available at https://authorea.com/users/376961/articles/493774-on-wellposedness-of-a-magnetization-variables-model-for-navier-stokes-equations-with-damping

\section{Hosted file}

wileyNJD-Doc.tex available at https://authorea.com/users/376961/articles/493774-on-wellposedness-of-a-magnetization-variables-model-for-navier-stokes-equations-with-damping 